IN early 1989 the authors began a series of discussions about the problem of the federal budget and how research has contributed to understanding its dynamic. Each of us had devoted several years to understanding the forces that have shaped the budget. One of us had spent most of his professional career researching and writing about the federal budget process. The others had served as policy officials at the Office of Management and Budget. What brought us together was a shared recognition that the rapidly rising national debt is one of the most serious financial problems facing the country and the belief that much of the problem stems not just from the politics of the budget, but from the institutional structure within which budget decisions are made.

We believe that, although research over the years has contributed much to understanding the powerful dynamics that drive the budget, the complexity of the budget and the congressional process requires a new approach to advance the frontiers of knowledge regarding the budget. The approach emphasizes micro rather than macro budgeting. It studies the budget as a system of interrelated but separate decisions that determine spending levels on individual programs and groups of programs. It focuses on the committee system, the rules and procedures Congress uses, the way in which budget outcomes are measured and reported to the public, and how the factors interact to produce budget outcomes. This book is the first product of our effort toward research on microbudgeting. It was written before President Clinton took office and therefore contains no reference to the Clinton administration. The Clinton administration's first year is now com- 


\section{vi Preface}

plete, and we believe that its results do not alter in any way the strength or force of the conclusions we reach in the individual chapters.

We gratefully acknowledge the financial support of the Smith Richardson Foundation through grants to the Hoover Institution. 